\title{
Molecular Mechanism of Cell Death Induced by the Antioxidant tert- Butylhydroxyanisole in Human Monocytic Leukemia U937 Cells
}

\author{
Tomoko OKuBo, ${ }^{*, a}$ Yoshiko YoKoYama, ${ }^{b}$ Kazutaka Kano, ${ }^{b}$ and Itsu Kano ${ }^{a}$ \\ ${ }^{a}$ Department of Environmental Health and Toxicology, Tokyo Metropolitan Institute of Public Health; 3-24-1 Hyakunin- \\ cho, Shinjuku-ku, Tokyo 169-0073, Japan: and ${ }^{b}$ Division of Molecular Epidemiology, Graduate School of Medicine, Kobe \\ University; 7-5-1 Kusunoki-cho, Chuo-ku, Kobe, Hyogo 650-0017, Japan. \\ Received August 18, 2003; accepted November 18, 2003
}

\begin{abstract}
A phenolic antioxidant 3-tert-butyl-4-hydroxyanisole (BHA) is a widely used food additive. BHA had cytotoxicity in human monocytic leukemia U937 cells. BHA at 0.75 mM caused nuclear condensation and fragmentation, structural damage in mitochondria, decrease in mitochondrial transmembrane potential, and internucleosomal DNA cleavage. It induced the activities of caspase-3 and/or -7, -6, -8 and -9, especially high when DEVDMCA was the substrate (caspase-3 and/or -7). DEVDase activity increased in time- and dose-dependent manner and high activity was observed in lysates of cells treated for $3 \mathrm{~h}$ at $0.75 \mathrm{~mm}$. Addition of GSH (reduced glutathione) during the treatment of cells with BHA inhibited the induction of DEVDase activity, and the intracellular GSH level decreased as the concentration of BHA was raised. Intracellular ATP levels decreased in time- and dose-dependent manner when the cells were treated with BHA in the presence or absence of glucose. Enzyme activities involved in the respiratory chain were assayed with the mitochondrial fraction prepared from U937 cells. BHA distinctly inhibited NADH-ubiquinone oxidoreductase (complex I) and cytochrome c oxidase (complex IV) at low concentrations. Succinate-ubiquinone oxidoreductase (complex II) was also inhibited, but to somewhat less extent. Without mitochondrial enzymes, BHA stimulated the ubiquinol-dependent reduction of cytochrome c (complex III), but it might have some detrimental effects on the mitochondrial enzyme reaction of complex III. The inhibition of mitochondrial oxidative phosphorylation might corroborate the mechanistic evidence for apoptosis of leukemia cells by BHA. Cell death induced by BHA is primarily ascribable to apoptosis.
\end{abstract}

Key words caspase; DNA ladder; mitochondrial transmembrane potential; apoptosis; oxidative phosphorylation; tert-butylhydroxyanisole

3-tert-Butyl-4-hydroxyanisole (BHA) is an antioxidant that is widely used in many countries as a food additive because its toxicity is regarded as low. Acceptable daily intake (ADI) prescribed by the Joint FAO/WHO Food Standard Program for BHA is $0-0.5 \mathrm{mg} / \mathrm{kg} / \mathrm{d}$. Daily intake of BHA in Japan in fiscal year 1996 was $0.105 \mathrm{mg}$ per person, ${ }^{1)}$ which corresponds to only about $0.4 \%$ of the ADI assuming a body weight of $50 \mathrm{~kg}$. Estimated daily intake of BHA is very low in the Netherlands, ${ }^{2)}$ Italy, ${ }^{3)}$ and Brazil. ${ }^{4}{ }^{4}$ However, since BHA is known to accumulate in adipose tissues, ${ }^{5}$ its effect on humans is a matter of great concern.

Dietary BHA was found to reduce the incidence of colon cancer induced by methylazoxymethanol acetate in female CF1 mice. $\left.{ }^{6}\right)$ BHA significantly reduced the genotoxic effects, such as the frequency of 6-thioguanidine resistant mutations and micronuclei, induced by $N$-methyl- $N^{\prime}$-nitro- $N$-nitrosoguanidine (MNNG) in Chinese hamster V79 cells. ${ }^{7)}$ Exercise-induced thymocyte apoptosis in rats was blocked by treatment with $\mathrm{BHA}^{8}{ }^{8} \mathrm{BHA}$ also inhibited tumor necrosis factor (TNF)-induced cytotoxicity in mouse fibrosarcoma cells, ${ }^{9,10)}$ and apoptosis induced by oxidative stress in neurons, ${ }^{11)}$ human leukemia cells, ${ }^{12)}$ and human monocytes and macrophages. ${ }^{13)}$

In contrast to the beneficial effects of BHA in animals or cultured cells, adverse effects have also been reported. At the dose of 0.5 or $2 \%(\mathrm{w} / \mathrm{w})$ in the diet, BHA induced papillomas and squamous cell carcinoma in the forestomach of rodents. ${ }^{14,15)}$ At doses that induce detoxifying enzymes, $15-$ $60 \mu \mathrm{M}$, it induced apoptosis in human colon carcinoma cells. ${ }^{16)}$ Cytotoxic effects have been observed in human dermal fibroblasts, keratinocytes, melanocytes, and melanoma tumor cells. ${ }^{17)}$ Its cytotoxicity in rat hepatocytes was attributed to the induction of apoptosis through a molecular mechanism of direct release of cytochrome $\mathrm{c}$ and subsequent activation of caspases. ${ }^{18)}$ These beneficial and adverse effects of BHA might depend on its concentration and also on the nature of cells or tissues.

Fusi et al. ${ }^{19)}$ reported that BHA has a number of effects, that is, it increases proton leak through the mitochondrial inner membrane and inhibits the $\Delta \mathrm{p}$ (proton motive force across the mitochondrial inner membrane) generating system, but it has no effect on the phosphorylation system. BHA is cytotoxic to isolated rat hepatocytes and inhibits state 3 and slightly stimulates state 4 of mitochondrial respiration. ${ }^{20)}$ It also dissipates mitochondrial transmembrane potential and causes the release of calcium ions, mitochondrial swelling, and decrease in ATP levels in intact hepatocytes. ${ }^{20)}$ Though the cytotoxicity of BHA and its effects on mitochondria have been extensively studied, the biochemical mechanism of cell death caused by BHA is not yet fully understood. Further study such as analysis of the site where BHA influences cellular function is required to elucidate the precise mechanism of action.

In the present study, we investigated the pathways of cell death induced by BHA by examining caspase activity and cellular morphology and by the estimation of individual mitochondrial enzyme activities involved in oxidative phosphorylation, which plays the major role in the maintenance of mitochondrial structure and function, in human monocytic leukemia U937 cells which are frequently used in cytotoxicity studies. ${ }^{21,22)}$ 


\section{MATERIALS AND METHODS}

Materials BHA was purchased from Fluka Chemical. RPMI 1640 medium was obtained from GIBCO-BRL. Fetal calf serum (FCS) was from Intergen (U.S.A.). Decylubiquinone (DB), 2,6-dichlorophenolindophenol sodium salt hydrate (DCPIP), 2-theonyl trifluoroacetone (TTFA), rotenone, antimycin $\mathrm{A}$, cytochrome $\mathrm{c}, \mathrm{NADH}, n$-dodecyl- $\beta$ D-maltoside, and PMSF were purchased from Sigma Chemicals. Agarose for electrophoresis, NuSieve 3:1, was from FMC BioProducts. SYBR Green and 5,5',6,6'-tetrachloro1,1',3,3'-tetraethylbenzimidazolcarbocyanine iodide (JC-1) were from Molecular Probes. Ac-DEVD-MCA, Ac-YVADMCA, Ac-VEID-MCA, Ac-DMQD-MCA, Ac-IETD-MCA, Ac-LEHD-MCA, and 7-amino-4-methylcoumarin (AMC) were obtained from Peptide Institute, Inc. (Osaka, Japan). Anti-poly(ADP-ribose) polymerase (PARP) antibody, clone C2-10, was purchased from BIOMOL Research Laboratories, Inc. (U.S.A.) and horseradish peroxidase-labeled goat antibody, $\mathrm{F}\left(\mathrm{ab}^{\prime}\right)_{2}$ fragment to mouse $\operatorname{IgG}(\mathrm{H}+\mathrm{L})$, was obtained from Kirkegaard \& Perry Laboratories Inc.

Cell Culture Human monocytic leukemia U937 cells were cultured with RPMI 1640 supplemented with 10\% (v/v) FCS and antibiotics, gentamycin sulfate, and kanamycin at $100 \mu \mathrm{g} / \mathrm{ml}$ each, at $37^{\circ} \mathrm{C}$ under $5 \% \mathrm{CO}_{2}$ in air.

Cytotoxicity Cytotoxicity was determined by the measurement of LDH (lactate dehydrogenase) activity released from cells into the culture medium at $3 \mathrm{~h}$ after the addition of BHA with LDH Cytotoxicity Detection Kit (Takara Biochemicals) according to the manufacturer's protocol with $2 \times 10^{4}$ cells in $200 \mu \mathrm{l}$ of medium/well. One hundred microliters of medium was taken to determine LDH activity and the absorbance at $492 \mathrm{~nm}$ was measured with the reference at $620 \mathrm{~nm}$. The percentage of LDH released in the growth medium, expressed as a function of total LDH release after the addition of Triton X-100 (final concentration 1\% (v/v)), was used as the index of cytotoxicity.

Examination of the Morphology of Cells Cells were treated for $3 \mathrm{~h}$ with BHA at $0.75 \mathrm{~mm}$, stained with $4^{\prime}, 6$-diamidino-2-phenylindole dihydrochloride (DAPI), and then examined by fluorescence microscopy at the magnification of $400 \times$.

Cytoarchitectural characteristics were examined by means of electron microscopy. The growth medium was removed after treatment of cells with or without BHA for $3 \mathrm{~h}$ and replaced with $\mathrm{PBS}, \mathrm{pH} 7.4$, containing $2 \%(\mathrm{w} / \mathrm{v})$ glutaraldehyde. Further fixation was carried out for $1 \mathrm{~h}$ with potassium ferricyanide in $1 \%(\mathrm{w} / \mathrm{v})$ osmium tetroxide. Specimens were stained with $2 \%(\mathrm{w} / \mathrm{v})$ aqueous uranyl acetate for $2 \mathrm{~h}$ and washed with water. Dehydration was performed with acetone, and cells were embedded in a mixture of epoxy resin and acetone. Samples were examined in a Hitachi H7100 TEM microscope at $75 \mathrm{kV}$. Photographs were taken at magnifications of 3200 and 24000.

Flow Cytometry Cells were stained with $5 \mu \mathrm{g} / \mathrm{ml}$ of JC1, a sensitive and specific fluorescent probe for mitochondrial transmembrane potential $(\Delta \psi),{ }^{23)}$ at room temperature for $20 \mathrm{~min}$, and mitochondrial permeability transition $(\Delta \psi)$ was analyzed using a FACScalibur flow cytometer (Becton Dickinson, U.S.A.) equipped with a single $488 \mathrm{~nm}$ argon laser. The filter at the FL1 photomultiplier was $530 \mathrm{~nm}$ with a bandwidth of $30 \mathrm{~nm}$, and that at FL2 was $585 \mathrm{~nm}$ with a bandwidth of $42 \mathrm{~nm}$. The photomultiplier values of the detector in FL1 and FL2 were set at $376 \mathrm{~V}$ and $330 \mathrm{~V}$, respectively. The compensations of FL1-FL2 and FL2-FL1 were 2.6\% and $19.5 \%$, respectively. A minimum of 10000 cells per sample were acquired and the data were analyzed with CELLQuest software (Becton Dickinson).

Analysis of DNA Fragmentation by Gel Electrophoresis DNA was isolated by the method reported by Hayashi et $a l{ }^{13)}$ with some modifications. Briefly, U937 cells $\left(1 \times 10^{6}\right.$ cells $/ \mathrm{ml}$ of culture medium) were treated with $0.75 \mathrm{~mm}$ BHA for 1.5 or $3 \mathrm{~h}$, collected, and then washed once with PBS by centrifugation. The pellet was treated at $4{ }^{\circ} \mathrm{C}$ for $10 \mathrm{~min}$ with $100 \mu \mathrm{l}$ of cold lysis buffer containing $0.5 \%(\mathrm{v} / \mathrm{v})$ Triton X$100,20 \mathrm{~mm}$ Tris- $\mathrm{HCl}$ (pH 7.5), and $2 \mathrm{~mm}$ EDTA. The supernatant after centrifugation at $12000 \times \boldsymbol{g}$ for $15 \mathrm{~min}$ was incubated at $37^{\circ} \mathrm{C}$ with RNase A for $1 \mathrm{~h}$ and then for a further $1 \mathrm{~h}$ with proteinase K. DNA was precipitated at $-20^{\circ} \mathrm{C}$ for $1 \mathrm{~h}$ in $50 \%(\mathrm{v} / \mathrm{v})$ isopropanol and $0.5 \mathrm{M} \mathrm{NaCl}$. Fragmented DNA was recovered by centrifugation. Agarose gel electrophoresis was carried out in $1.7 \%$ NuSieve $3: 1$ and bands were stained with SYBR Green. Each lane contains DNA corresponding to the amount extracted from $4 \times 10^{5}$ cells.

Assay of Caspase Protease Activities U937 cells inoculated at $2 \times 10^{6}$ cells $/ \mathrm{ml}$ medium in $35-\mathrm{mm}$ dishes were incubated in the presence or absence of BHA. To examine the effect of GSH (reduced glutathione), GSH was dissolved in distilled water and added to the culture medium before the addition of $0.75 \mathrm{~mm}$ BHA. After incubation with BHA, the cells were collected and washed with PBS without $\mathrm{Ca}^{++}$or $\mathrm{Mg}^{++}$. The lysis buffer $(100 \mu \mathrm{l})$, consisting of Tris- $\mathrm{HCl}(\mathrm{pH}$ $7.5)$ and $0.2 \%(\mathrm{v} / \mathrm{v})$ Triton $\mathrm{X}-100$, was added to the cells and the mixture was kept at $4{ }^{\circ} \mathrm{C}$ for $30 \mathrm{~min}$. The lysate was obtained as the supernatant after centrifugation at $12000 \times \boldsymbol{g}$ for $10 \mathrm{~min}$. The enzyme activity was assayed as described previously, ${ }^{21)}$ with substrate concentrations of $50 \mu \mathrm{M}$ for AcDEVD-AMC and $100 \mu \mathrm{M}$ for other substrates, and expressed as the amount of AMC cleaved per mg protein per min. Each activity was calculated by subtracting the control value obtained in the reaction with the lysates of cells treated with vehicle alone (DMSO) in the culture medium. Exceptionally, in dose-response and time-course experiments with BHA, DEVDase activity was expressed without correction. The protein concentration of the lysate was determined with a BioRad DC protein assay system. Statistical significance analysis was determined using the two-tailed Student's $t$-test (a $p$ value of $<0.01$ was considered significant).

Western Blotting of Poly(ADP-ribose) Polymerase (PARP) Protein Cells were dissolved in a solution ${ }^{24)}$ containing $62.5 \mathrm{~mm}$ Tris- $\mathrm{HCl}, \mathrm{pH} 6.8,6 \mathrm{~m}$ urea, 10\% (v/v) glycerol, $2 \%(\mathrm{w} / \mathrm{v})$ SDS, $5 \%(\mathrm{v} / \mathrm{v}) \quad \beta$-mercaptoethanol, and $0.003 \%(\mathrm{w} / \mathrm{v})$ bromophenol blue by sonication for $60 \mathrm{~s}$ with a Branson Sonifier B-12 (Danbury, Conn., U.S.A.) on ice. Twenty micrograms of protein was subjected to $7.5 \%$ SDSPAGE and protein bands were transferred with a Semi-dry Transfer Cell (Transblot SD, Bio-Rad) to PVDF membrane (Hybond-P, Amersham Biosciences). After reaction with the primary antibody and peroxidase-conjugated second antibody in PBS containing $0.1 \%(\mathrm{v} / \mathrm{v})$ Tween-20 and 5\% (w/v) non-fat powdered milk (Block Ace Powder, Dainippon Pharmaceutical Co., Ltd.), the bands of peptides were visualized 
by chemiluminescent reagents (ECL plus, Amersham Biosciences) on Polaroid 667 film in Camlight 501 (Analytical Luminescence Laboratory, U.S.A.).

Determination of Reduced Glutathione Cytosolic reduced glutathione was determined by a fluorometric method $^{25)}$ with slight modification. Briefly, U937 cells were collected in a tube after treatment with BHA and washed with PBS. GSH was extracted with cold 5\% (v/v) perchloric acid. After the addition of $o$-phthalaldehyde, fluorescence with excitation at $350 \mathrm{~nm}$ and emission at $420 \mathrm{~nm}$ was measured with a Cytofluor II plate reader (Applied Biosystems). Protein was estimated by dissolving the acid precipitate in $\mathrm{NaOH}$ solution.

Preparation of Mitochondria U937 cells $\left(2 \times 10^{7}\right)$ were collected, washed three times with $20 \mathrm{~mm}$ HEPES, pH 7.4, containing $300 \mathrm{~mm}$ mannitol, $1 \mathrm{~mm}$ EDTA and $0.1 \mathrm{~mm}$ PMSF and homogenized in the same buffer with 40 strokes in a glass-Dounce homogenizer (tight) on ice. The supernatant obtained by centrifugation at $600 \times \boldsymbol{g}$ for $5 \mathrm{~min}$ was further centrifuged at $8000 \times \boldsymbol{g}$ for $20 \mathrm{~min}$ to remove microsomes. The precipitate was washed by centrifugation at $8000 \times \boldsymbol{g}$ for $20 \mathrm{~min}$. The mitochondrial fraction was dissolved in the same buffer and stored at $-80^{\circ} \mathrm{C}$ until use.

Assay of Respiratory Complexes Activities of individual enzymes of the mitochondrial respiratory chain were estimated essentially according to the methods of Cornelissen et al., ${ }^{26)}$ Trounce et al., ${ }^{27)}$ and Cardoso et al. ${ }^{28)}$ with modifications. BHA was added to the reaction mixture at the beginning of incubation. Each reaction was performed at $30^{\circ} \mathrm{C}$. For the assay of complexes I, II, III, and IV, a Shimadzu Spectrophotometer Type UV-300 was used, and the activity was expressed as $\mathrm{nmol} / \mathrm{mg}$ protein $/ \mathrm{min}$.

In the case of complex I activity, mitochondrial fraction ( $20 \mu \mathrm{g}$ of protein) was incubated in a mixture containing $50 \mathrm{~mm}$ Tris- $\mathrm{HCl}$ buffer, pH 7.4, $1 \mathrm{~mm}$ EDTA, $250 \mathrm{~mm}$ sucrose, $2 \mathrm{~mm} \mathrm{KCN}, 10 \mu \mathrm{M}$ decylubiquinone (DB) and $0.6 \mathrm{~mm}$ $n$-dodecyl- $\beta$-D-maltoside. After a 1 -min preincubation, the reactions were started by the addition of $50 \mu \mathrm{M}$ NADH. Rotenone $(5 \mu \mathrm{g} / \mathrm{ml})$ sensitive activity was regarded as complex I activity. Oxidation of NADH was monitored at $340 \mathrm{~nm}$ with the reference at $380 \mathrm{~nm}$.

In the case of complex II activity, mitochondrial fraction $(25 \mu \mathrm{g})$ was incubated in $50 \mathrm{~mm}$ potassium phosphate buffer, $\mathrm{pH} 7.4$, supplemented with $20 \mathrm{~mm}$ succinate, $2 \mathrm{~mm} \mathrm{KCN}$, $2 \mu \mathrm{g} / \mathrm{ml}$ antimycin A, $4 \mu \mathrm{g} / \mathrm{ml}$ rotenone, $0.6 \mathrm{~mm} n$-dodecyl- $\beta$ D-maltoside, and $50 \mu \mathrm{M}$ DCPIP. After a 2-min equilibration, the reaction was started by addition of $50 \mu \mathrm{M}$ DB to the reaction mixture, and the decrease in absorbance at $600 \mathrm{~nm}$ with the reference at $750 \mathrm{~nm}$ was monitored. TTFA $(0.5 \mathrm{~mm})$ sensitive activity was regarded as complex II activity.

Complex III donates electrons from reduced decylubiquinone (ubiquinol) to cytochrome $\mathrm{c}$, leading to the reduction of cytochrome c. Ubiquinol was prepared by reducing DB with sodium dithionite. ${ }^{26)}$ The complex III assay mixture contained $25 \mathrm{~mm}$ potassium phosphate buffer, $\mathrm{pH} 7.2,1 \mathrm{~mm}$ EDTA, $2.5 \mathrm{~mm} \mathrm{MgCl}_{2}, 0.6 \mathrm{~mm} n$-dodecyl- $\beta$-D-maltoside, $2 \mathrm{~mm} \mathrm{KCN}$, and $50 \mu \mathrm{M}$ cytochrome c. After a 1-min preincubation, the reaction was started by the addition of $50 \mu \mathrm{M}$ ubiquinol. The increase in absorbance was monitored at $550 \mathrm{~nm}$ with the reference at $540 \mathrm{~nm}$. Antimycin A $(5 \mu \mathrm{g} / \mathrm{ml})$ sensitive activity was regarded as complex III activity. The effect of BHA on the apparent activity of complex III was determined in the absence of mitochondrial preparation with various concentrations of BHA in the reaction mixture.

Complex IV activity was estimated by measuring the oxidation of reduced cytochrome $\mathrm{c}$. Reduced cytochrome $\mathrm{c}$ was prepared according to the method of Trounce et al. ${ }^{27)}$ The reaction mixture contained $25 \mathrm{~mm}$ potassium phosphate buffer, pH 7.4, $1 \mathrm{~mm} n$-dodecyl- $\beta$-D-maltoside, and $20 \mu \mathrm{M}$ reduced cytochrome c. After a $1-\mathrm{min}$ preincubation, the reaction was started by addition of $48 \mu \mathrm{g}$ of mitochondria. The decrease in absorbance was monitored at $550 \mathrm{~nm}$ with the reference at $540 \mathrm{~nm}$. KCN (2 mM) sensitive activity was regarded as the complex IV activity.

Determination of Cellular ATP Level ATP was determined luminometrically with a Bioluminescence Assay Kit CLS II (Roche Diagnostics GmbH). In the case of glucosefree medium, collected cells were washed twice with glucose-free RPMI 1640 medium and incubated in a $\mathrm{CO}_{2}$ incubator for $30 \mathrm{~min}$ before plating cells. Cells treated with BHA in glucose-containing RPMI 1640 medium ( $2 \mathrm{~g} / 1)$ or glucosefree medium were dissolved in lysis buffer $(100 \mathrm{~mm}$ Tris, $4 \mathrm{~mm}$ EDTA, $\mathrm{pH}$ 7.75) and boiled for $1 \mathrm{~min}$. The supernatant obtained by centrifugation at $12000 \mathrm{rpm}$ for $1 \mathrm{~min}$ was taken for the determination of ATP in a Luminometer LB96V (Wallac/Berthold).

\section{RESULTS}

Cytotoxicity of BHA Cytotoxicity of BHA estimated by the release of LDH in the culture medium increased dose-dependently from $3 \times 10^{-5} \mathrm{M}$ to $3 \times 10^{-3} \mathrm{M}$, reaching higher than $80 \%$ with $3 \times 10^{-3} \mathrm{M}$ BHA after treatment of cells for $3 \mathrm{~h}$ (Fig. 1).

Morphology of the Cells In BHA-treated cells, nuclei were condensed and fragmented, while control cells treated with vehicle alone were not stained with DAPI (Fig. 2A).

Nuclear condensation and fragmentation in cells after the treatment with $0.75 \mathrm{~mm}$ BHA for $3 \mathrm{~h}$ was also confirmed by electron microscopy (Fig. 2B-1). Higher magnification (Fig. 2B-2) demonstrated that mitochondrial structure was disrupted as compared with non-treated control cells. Degradation of cristae and mitochondrial membrane, and discontinuous structure of mitochondrial membrane were frequently observed. Single-layered mitochondrial membrane with almost total loss of intramitochondrial structure or vacuole-like structure was also detected.

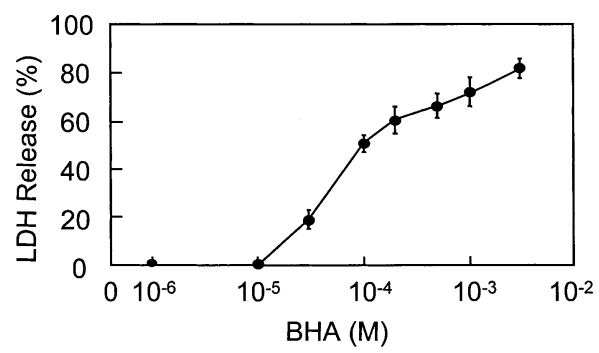

Fig. 1. Cytotoxicity of BHA Was Determined by the Measurement of LDH Activity Released in the Medium with 1\% FCS during the Treatment of Cells for $3 \mathrm{~h}$

Values are the percentage of release of LDH, where $100 \%$ is the value obtained by the treatment of cells with $1 \%(\mathrm{v} / \mathrm{v})$ Triton X-100. Mean \pm S.D. $(n=6)$. 
(A)

CONTROL

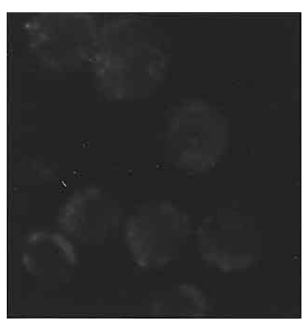

(B-1)

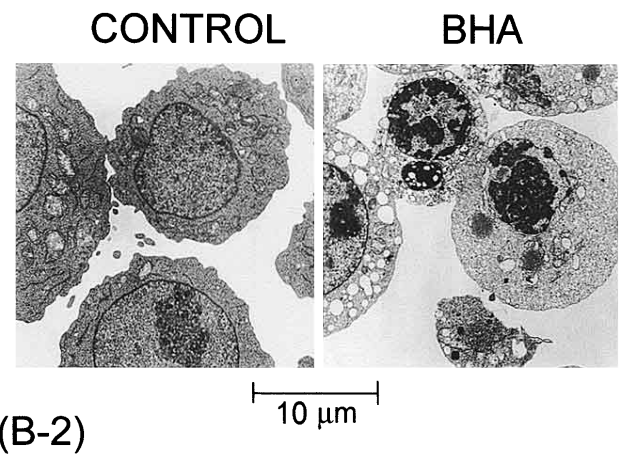

CONTROL

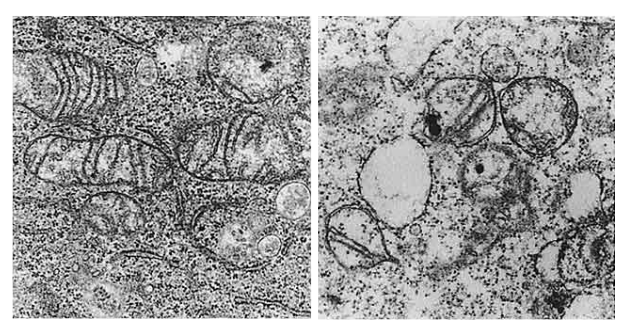

Fig. 2. (A) Fluorescence Microscopic Examination of Cells Treated with $0.75 \mathrm{~mm}$ BHA for $3 \mathrm{~h}$ and Stained with DAPI

Control cells were treated with vehicle ( $0.1 \%$ DMSO) alone.

(B) Electron Microscopic Analysis of U937 Cells Treated with or without $0.75 \mathrm{~mm}$ BHA for $3 \mathrm{~h}$

(B-1) $\times 3200$ magnification. The size marker was $10 \mu \mathrm{m}$. (B-2) $\times 24000$ magnification.

Assessment of Mitochondrial Transmembrane Potential with Flow Cytometry When the cells were stained with JC-1 and analyzed by flow cytometry, most signals in control cells were detected as high fluorescence of FL2 in the upper part $(88 \%)(81+7)$, forming JC-1 aggregates. On the other hand, signals in the upper part decreased to $8 \%(5+3)$ after treatment of cells with $0.75 \mathrm{~mm}$ BHA for $1 \mathrm{~h}$, concomitantly with their increase in the lower part $(92 \%)(67+25)$ (Fig. 3). The decrease in JC-1 aggregates indicated the disruption of mitochondrial transmembrane potential. The increase in signals in the upper and lower right quadrants from about $8 \%(7+<1)$ to $28 \%(3+25)$ after the treatment of cells with BHA indicated a small shift of signals to higher FL1, which implied an increase in JC-1 monomers. When the cells were treated with BHA for a longer period $(3 \mathrm{~h})$, the fluorescence intensity of FL2 was lowered too drastically to detect signals in the plot area (data not shown).

DNA Ladder Formation on Agarose Gel Electrophoresis Characteristic internucleosomal DNA fragmentation was detected with $0.75 \mathrm{~mm}$ BHA at two time-points, 1.5 and
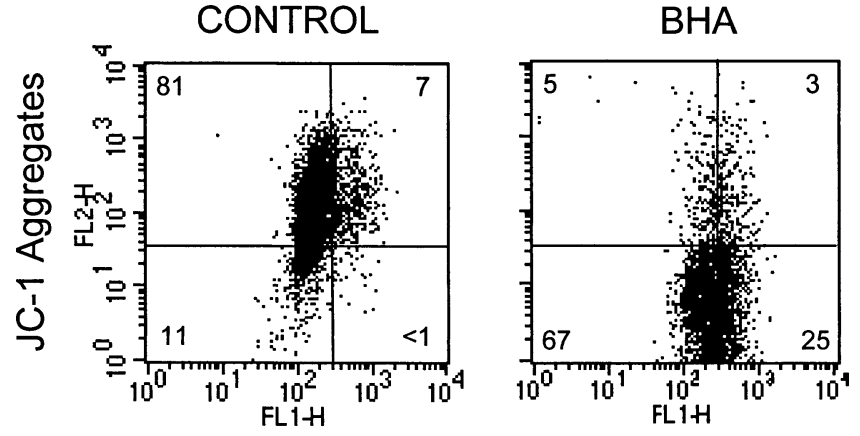

\section{JC-1 Monomers}

Fig. 3. FACS Analysis of Mitochondrial Transmembrane Potential of Cells Stained with JC-1 after Treatment with $0.75 \mathrm{~mm}$ BHA for $1 \mathrm{~h}$

A representative result of 3 experiments is shown. Numbers refer to the percentage of cells encountered in each area.

\section{std cont $1.53 \mathrm{~h}$}

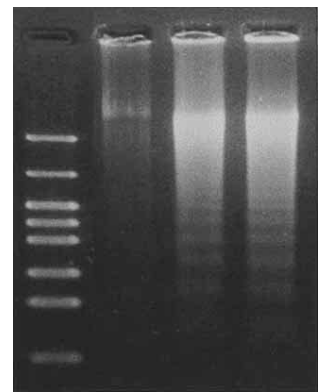

Fig. 4. DNA Ladder Formation

A representative pattern of agarose gel electrophoresis performed more than 5 times is shown. U937 cells were treated with $0.75 \mathrm{~mm}$ BHA for 1.5 and $3 \mathrm{~h}$ ( 2 right lanes). Control (cont) is sample treated with DMSO for $3 \mathrm{~h}$. Each lane contains DNA corresponding to the amount extracted from $4 \times 10^{5}$ cells. Left lane (std) is pHY size marker.
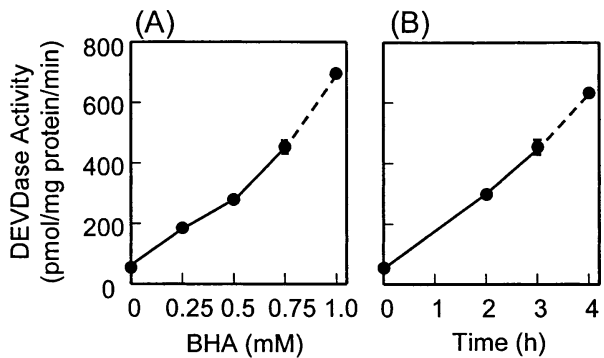

Fig. 5. DEVDase Activity Induced by the Treatment of Cells with BHA

(A) Dose-response curve in 3-h treatment. (B) Time course data with 0.75 mM BHA. Though the apparent specific activity was high at $1 \mathrm{~mm}(\mathrm{~A})$ and at $4 \mathrm{~h}(\mathrm{~B})$, protein recovery was extremely low because of severe damage to the cells at these points (shown by dotted lines). Values are means \pm S.D. $(n=4)$, but S.D. values are within the size of symbols.

$3 \mathrm{~h}$ (Fig. 4). Fragmented bands seemed to increase with time, while they were not found in control.

Enzyme Activities of Caspases DEVDase (caspase-3 and/or -7) activity increased as the concentration of BHA was raised, when cells were treated for $3 \mathrm{~h}$ (Fig. 5A). In the time-course experiments with $0.75 \mathrm{~mm}$ BHA, the activity increased with the length of treatment (Fig. 5B). The recovery of protein up to $0.75 \mathrm{~mm}$ or $3 \mathrm{~h}$ was almost unchanged from that of control cells. However, it was extremely low with $1 \mathrm{~mm}$ BHA or at $4 \mathrm{~h}$, probably because many cells died of cy- 
Table 1. Caspase Activities after Treatment of U937 Cells with $0.75 \mathrm{~mm}$ BHA for $3 \mathrm{~h}$

\begin{tabular}{llcc}
\hline \hline Substrate & Caspase specificity & Control & BHA-treated \\
& & \multicolumn{2}{c}{$(\mathrm{pmol} / \mathrm{mg}$ protein $/ \mathrm{min})$} \\
& & $88.2 \pm 6.6$ & $86.5 \pm 2.0$ \\
YVAD & 1,4 & $47.5 \pm 1.7$ & $460.5 \pm 11.4^{* *}$ \\
DEVD & 3,7 & $66.1 \pm 3.6$ & $132.7 \pm 19.0^{*}$ \\
DMQD & 3 & $190.4 \pm 7.3$ & $342.3 \pm 14.8^{* *}$ \\
VEID & 6 & $108.4 \pm 3.8$ & $193.6 \pm 4.3^{* *}$ \\
IETD & 8,6, Granzyme B & $30.9 \pm 7.8$ & $56.3 \pm 7.6^{*}$ \\
LEHD & 9 & & \\
\hline
\end{tabular}

Control activities were the values with lysates of cells treated with DMSO alone in the growth medium. Asterisks denote statistically significant difference when compared to the control values $(* * p<0.001, * p<0.01)$. Each value is mean \pm S.D. $(n=4)$.

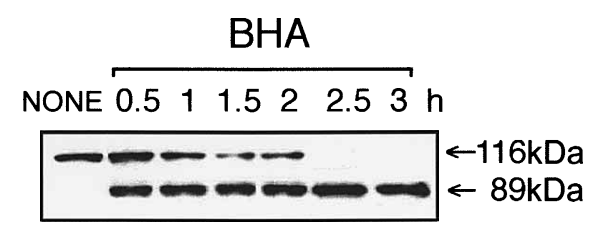

Fig. 6. Western Blotting of PARP Demonstrating the Cleavage after the Treatment of Cells with BHA

Twenty micrograms of protein at each time point, $0,0.5,1,1.5,2,2.5$ and $3 \mathrm{~h}$, was applied onto the $7.5 \%$ SDS-PAGE gel. PARP peptide was detected as described in the Materials and Methods.

tolysis, and the apparent specific activity (activity/mg protein/min) was very high (shown with dotted lines in Fig. 5).

Since the activity of DEVDase was highly induced after treatment of cells with $0.75 \mathrm{~mm}$ BHA for $3 \mathrm{~h}$, enzyme activities towards various caspase substrates were also examined (Table 1). Caspase activities towards DMQD, VEID, IETD, and LEHD were induced, but only to a small extent compared to DEVDase. In contrast, YVADase was barely induced.

Cleavage of PARP in Cells Treated with BHA PARP is one of the targets of DEVDase since it contains the DEVD peptide sequence. The cleavage of PARP was observed in the cells treated with BHA. In addition to the original 116-kDa PARP protein, an 89-kDa peptide was detected (Fig. 6). Considerable cleavage occurred as early as $0.5 \mathrm{~h}$, and almost all the $116-\mathrm{kDa}$ peptide was cleaved at $2.5 \mathrm{~h}$. The cleavage might indicate the activation of DEVDase in BHA-treated cells.

Effect of GSH on DEVDase Induction by BHA GSH was included in the medium during treatment of cells with BHA for $3 \mathrm{~h}$. When the concentration of GSH was higher than $10 \mathrm{~mm}$ in the growth medium, the induction of DEVDase activity was sharply decreased (Fig. 7A). Almost complete inhibition was observed by about $25 \mathrm{~mm}$ GSH.

Intracellular GSH Level Intracellular thiol levels in the nonprotein fraction represent GSH. When the GSH level was estimated after treatment of cells for $3 \mathrm{~h}$ with various concentrations of BHA, it was barely affected by $0.5 \mathrm{~mm}$ BHA, but drastically decreased at $0.75 \mathrm{~mm}$ and $0.8 \mathrm{~mm}$ (Fig. 7B).

Effect of BHA on Mitochondrial Enzymes Involved in Oxidative Phosphorylation Among the individual enzyme complexes of the respiratory chain, the NADH-ubiquinone oxidoreductase (complex I) was severely inhibited by BHA (Fig. 8A). Its activity was decreased to approximately $50 \%$ of control at $0.1 \mathrm{~mm}$ and to less than $10 \%$ at $0.75 \mathrm{~mm}$. Cytochrome c oxidase (complex IV) was decreased to about
(A)

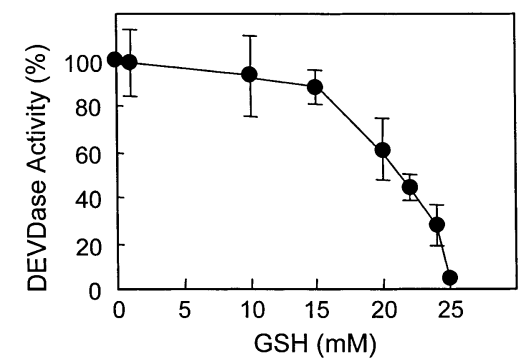

(B)

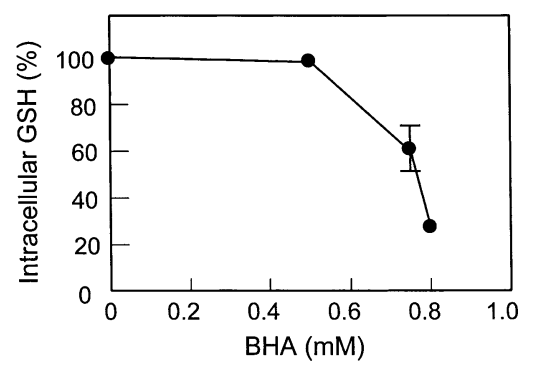

Fig. 7. Effect of GSH on DEVDase Induction (A) and Intracellular GSH Levels after Treatment of U937 Cells with BHA (B)

(A) Various concentrations of GSH were added with $0.75 \mathrm{~mm}$ BHA in the growth medium and cells were treated for $3 \mathrm{~h}$. Enzyme activity (\%) was corrected by subtracting the control value obtained in the reaction with the lysate of cells treated with DMSO in the growth medium. DEVDase activity in the absence of GSH was taken as $100 \%(413.0 \mathrm{pmol} / \mathrm{mg}$ protein $/ \mathrm{min})$. Values are means \pm S.D. $(n=4)$. (B) Intracellular GSH levels after treatment of cells with various concentrations of BHA for $3 \mathrm{~h}$. The value of control with DMSO was $10.7 \pm 0.14 \mathrm{nmol} / \mathrm{mg}$ protein $(100 \%)$. Values are means \pm S.D. $(n=4)$.

$55 \%$ of control with $0.25 \mathrm{~mm}$ BHA. BHA also inhibited succinate-ubiquinone oxidoreductase (complex II), but its inhibition was not as great as that of complex I or IV. BHA inhibited the oxidative enzyme reactions of complexes I, II, and $\mathrm{IV}$ in a concentration-dependent manner with $\mathrm{IC}_{50}$ values of approximately $0.1,1.25$, and $0.28 \mathrm{~mm}$, respectively.

The mitochondrial fraction catalyzed the reaction of ubiquinol-cytochrome $\mathrm{c}$ reductase (complex III) depending on the amount of protein added in the mixture (Fig. 8B-1). In the absence of mitochondrial enzymes, however, BHA distinctly stimulated the reduction of cytochrome $\mathrm{c}$ in a concentration-dependent manner in the presence of ubiquinol (Fig. 8B-2). Ubiquinol in the reaction mixture was indispensable because cytochrome $\mathrm{c}$ reductase was not activated by $2.0 \mathrm{~mm}$ BHA in the absence of ubiquinol without the mitochondrial fraction. BHA itself is an antioxidant and might catalyze the ubiquinol-dependent reduction of cytochrome c. When BHA was included in the reaction mixture in the presence of mitochondria, the reduction of cytochrome $\mathrm{c}$ was slightly inhibited by low concentrations of BHA, 0.25 and $0.5 \mathrm{~mm}$ (Fig. 8B-3). However, a small increase (about 20\%) in activity was observed with BHA at $2 \mathrm{~mm}$, whereas the activity was decreased to about $76 \%$ by the addition of antimycin A. Though antimycin A abolished the mitochondrial enzyme activity without BHA as expected (Fig. 8B-1), it only partly inhibited the activity in the presence of $2.0 \mathrm{~mm}$ BHA and mitochondria (Fig. 8B-3), indicating that the remaining activity was the BHA-induced reduction of cytochrome $\mathrm{c}$, but was not enzyme-dependent.

Effect of BHA on ATP Level Intracellular ATP level decreased as the concentration of BHA was raised when the 
(A)

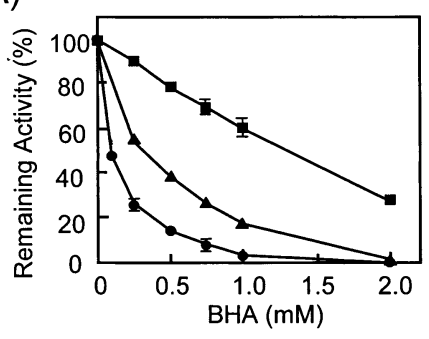

(B-1)

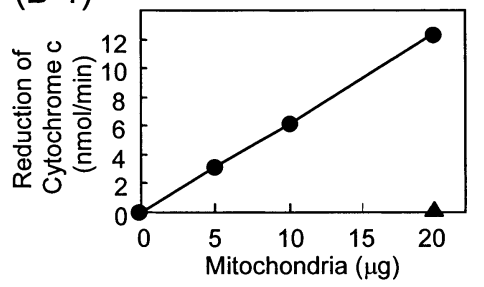

(B-2)

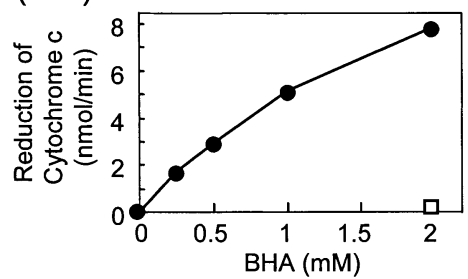

(B-3)

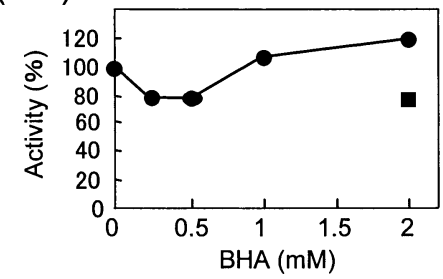

Fig. 8. (A) Inhibition of Enzyme Activities of Mitochondrial Oxidative Phosphorylation

Remaining activity (\%) was corrected by subtracting the value without the mitochondrial fraction, and the activities in the absence of $\mathrm{BHA}$ were taken as $100 \%$, which were $15.7,20.1$ and $20.6 \mathrm{nmol} / \mathrm{mg}$ protein/min for complex I (@), complex II (ם) and complex IV $(\boldsymbol{\Delta})$, respectively. Values are means \pm S.D. $(n=3)$, some of which are within the size of symbols.

(B) The Effect of BHA on Mitochondrial Complex III

(B-1) Effect of various concentrations of mitochondrial fraction on ubiquinol-cytochrome $\mathrm{c}$ reductase (complex III) without BHA in the presence of ubiquinol. Activity in the presence of antimycin A with $20 \mu \mathrm{g}$ of mitochondrial protein is shown $(\mathbf{\Delta})$. (B-2) Effect of various concentrations of BHA on the reduction of cytochrome $\mathrm{c}$ in the reaction mixture of complex III without mitochondrial fraction in the presence of ubiquino

(O). Activity in the absence of ubiquinol with 2 mm BHA ( $\square$ ) is shown. (B-3) Activity with mitochondrial fraction $(20 \mu \mathrm{g})$ and various concentrations of BHA, where $100 \%$ is the activity in the absence of BHA $(219 \pm 12 \mathrm{nmol} / \mathrm{mg}$ protein $/ \mathrm{min})$. Activity in the presence of antimycin A with 2 mM BHA (ם) is shown. Values are the means \pm S.D. $(n=3)$, which is less than $1.5 \%$.

cells were treated for $1 \mathrm{~h}$. A drastic decrease to less than $10 \%$ of the initial level was observed with BHA at $0.75 \mathrm{~mm}$ and $0.5 \mathrm{~mm}$ in the presence and absence of glucose, respectively (Fig. 9A). In the time-course experiment with $0.75 \mathrm{~mm}$ BHA, ATP decreased very rapidly, probably in less than $15 \mathrm{~min}$ (Fig. 9B), while its level was barely changed without BHA in the presence or absence of glucose. The decrease was even sharper in the absence of glucose (Figs. 9A, B).

\section{DISCUSSION}

The release of $\mathrm{LDH}$ in the medium is an indicator of the
(A)

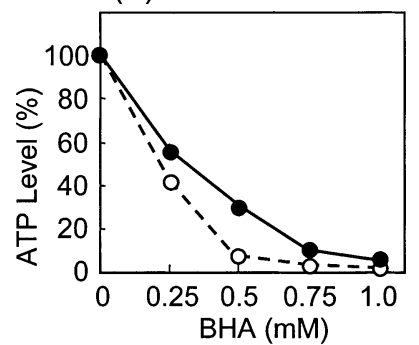

(B)

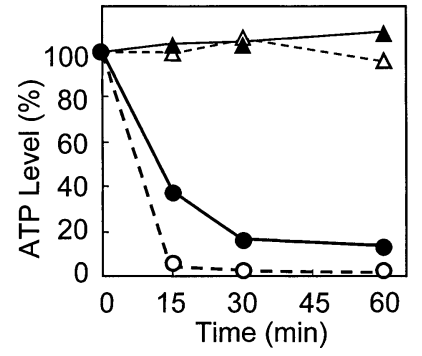

Fig. 9. Intracellular ATP Level

ATP level was determined in the absence of glucose $(O, \triangle)$ and in its presence ( $\boldsymbol{\Delta})$. The value of $100 \%$ in the absence of BHA was $2.52 \mathrm{nmol} / 10^{6}$ cells. (A) ATP was determined after treatment of cells for $1 \mathrm{~h}$ with various concentrations of BHA $(\mathrm{O}, \mathbf{0})$. (B) Time course of the decrease of ATP level with $0.75 \mathrm{~mm}$ BHA $(\bigcirc, \bullet)$ or without $\mathrm{BHA}(\triangle, \boldsymbol{\Delta})$. Values are representative of 4 experiments with duplicate determinations.

cytocidal response and represents the damage to cell integrity. Cytotoxicity of BHA observed in the range of concentration from $3 \times 10^{-5} \mathrm{M}$ to $3 \times 10^{-3} \mathrm{M}$ might correspond to the study by Thompson and Moldéus ${ }^{20)}$ which reported concentrations from 100 to $750 \mu \mathrm{M}$ in isolated rat hepatocytes. Internucleosomal cleavage observed as DNA ladder (Fig. 4) is one of the typical features of apoptosis induced by BHA.

Fragmented nuclei stained with DAPI (Fig. 2A) by the treatment of cells with BHA demonstrated the involvement of apoptotic processes in cytotoxicity of BHA. Electron microscopic analysis with higher magnification has shown that the mitochondrial structure was severely disrupted. Dissipation of $\Delta \psi \mathrm{m}$ in mitochondria is an early event in apoptosis. ${ }^{29)}$ We demonstrated that BHA induced the disruption of mitochondrial transmembrane potential by flow cytometry with JC-1, which is a specific dye for mitochondria not like DiOC6(3) staining plasma membrane as well as mitochondria. ${ }^{23)}$ Single-layered vacuole-like structures caused by BHA may be explained by the swelling and disruption of the mitochondrial membrane, which might represent "secondary necrosis" ${ }^{29)}$ following apoptosis.

Cysteine aspartases (caspases) are involved in cell death via apoptosis. ${ }^{30,31)} \mathrm{Yu}$ et al. ${ }^{18)}$ have shown that cytochrome $\mathrm{c}$ was released from mitochondria by treatment of rat hepatocytes with $0.5 \mathrm{~mm}$ BHA, and they concluded that cytotoxicity of BHA is due to the induction of apoptosis, which is mediated by the direct release of cytochrome $\mathrm{c}$ and subsequent activation of caspases. In the present study, DEVDase activity representing caspase- 3 and/or -7 was distinctly induced, and it was confirmed by the cleavage of PARP (Fig. 6). These results indicated a commitment to caspase-3 and/or -7-induced cell death. The significant increase in DMQDase activity (caspase-3 activity specific) upon treatment of cells with BHA (Table 1) provided evidence of the contribution of caspase-3. Induction of VEIDase (caspase-6), IETDase (cas- 
pase- 8 , -6 and granzyme B), and LEHD (caspase-9) activities suggested that BHA might contribute to the activation of all of the 'initiator' caspases (e.g., caspase-8, -9, and -10) and 'effector' caspases (e.g., caspase-3, -6 and -7) in apoptosis. ${ }^{31)}$

BHA has been reported to inhibit primarily the action of $\mathrm{NAD}^{+}$- and FAD-linked dehydrogenase systems, leading to the cessation of oxidative phosphorylation and a rapid depletion of the ATP supply, which, in turn would lead to a decrease in the activity of energy-dependent processes. ${ }^{32,33)}$ The question of which reaction of oxidative phosphorylation is affected by BHA has not been clearly answered. In the present study, by the assay of the individual enzyme complexes of oxidative phosphorylation, BHA was found to inhibit complexes I, II and IV (Fig. 8A). The effect of BHA on complex III was unique: BHA is an antioxidant and it stimulated the reduction of cytochrome $\mathrm{c}$ in the presence of ubiquinol without an enzyme (Fig. 8B-2). Since the inhibition of mitochondrial complex III activity by BHA at low concentration was observed (Fig. 8B-3), BHA obviously had a detrimental effect on the activity of complex III. Ubiquinol, reduced ubiquinone, itself is an antioxidant and prevents apoptotic features such as caspase activation, cytochrome c release, and disruption of mitochondrial transmembrane potential. ${ }^{34)}$ Physiologically, ubiquinol and ubiquinone are recycled in mitochondria to promote oxidative phosphorylation. However, the conversion of ubiquinol to ubiquinone, whose reaction is coupled with the reduction of cytochorome c via several steps, might be inhibited in the presence of BHA, and all of the processes of oxidative phosphorylation might be deranged. It was suggested that BHA blocked the electron flow by acting on multiple sites.

Intracellular GSH level was decreased by treatment of the cells with BHA (Fig. 7B) in the range of concentrations causing cytotoxicity and DEVDase activity. The reduction in glutathione level is a part of the sequence of events leading to apoptosis and occurs when the mitochondrial transmembrane potential is completely disrupted. ${ }^{29)}$ A condition causing GSH depletion culminates in a loss of mitochondrial function, particularly the decreases in activities of complexes I, II, and IV of the respiratory chain. ${ }^{35)}$ We observed that BHA had a potential to inhibit complexes I, II and IV (Fig. $8 \mathrm{~A}$ ) as mentioned above.

It has been shown that exogenous GSH is rapidly transported across the plasma membrane of renal cells. ${ }^{36,37)}$ The addition of GSH to U937 cells actually inhibited DEVDase activity (Fig. 7A), but the effective concentration was relatively high. The efficiency of exogenous GSH to exert its effect inside the cells may depend on cellular differences in transport ability. However, on the basis of the study on the effects of exogenous GSH, it is likely that GSH, at least partly, is involved in defense against apoptotic cell death by BHA.

ATP is required for the execution of apoptosis and the conditions of ATP depletion lead to necrosis. ${ }^{38)}$ In particular, when the ATP level drops below $15-25 \%$ of the control level, cells die of necrosis. ${ }^{39)}$ The ATP level was drastically lowered within $60 \mathrm{~min}$ by treatment of cells with BHA (Fig. 9). These results might correspond to those of Thompson and Moldéus $^{20)}$ who observed a rapid drop in ATP levels with $750 \mu \mathrm{M}$ BHA in rat hepatocytes. Drastic decrease in ATP with BHA at a concentration higher than $0.75 \mathrm{~mm}$ or at a later stage of treatment with $0.75 \mathrm{~mm}$ BHA (Fig. 9) may sug- gest that a large number of cells die of cytolysis. Cytolysis occurs secondary to apoptosis when dying cells fail to be removed by heterophagy. ${ }^{29)}$ A rapid and sharp drop in ATP might be ascribable to blocking of the steps in mitochondrial oxidative phosphorylation. Since the depletion of glucose accelerated the decrease in ATP, it is speculated that ATP generation in glycolysis (TCA cycle) was also inhibited by BHA.

In conclusion, BHA causes typical apoptosis of human monocytic leukemia U937 cells, with characteristic morphological changes that include nuclear fragmentation, internucleosomal DNA cleavage, caspase activation and decrease in mitochondrial transmembrane potential. GSH and ATP levels were decreased. The present study revealed that BHA inhibited the mitochondrial respiratory chain at multiple sites, complexes I, II, and IV, by the assay of individual enzyme complexes. It inhibited complex III as well, though BHA itself works as an electron-transferring compound and apparently stimulated the reduction of cytochrome c non-enzymatically in the presence of ubiquinol. BHA was found to inhibit mitochondrial oxidative phosphorylation and cause cell death, primarily through the series of events in the apoptotic cascade.

Apoptosis by BHA was most effectively observed at the rather high concentration of $0.75 \mathrm{~mm}$. However, since there is a report that it caused apoptosis at $15-60 \mu \mathrm{M}$ in human colon carcinoma cells, ${ }^{16)}$ it is plausible that versatile results could be obtained depending on the experimental systems. Moreover, molecular and cellular events caused by BHA, even at low concentrations, might eventually lead to apoptosis. The data in the present study with U937 cells, a type of human cancerous cell, would be instrumental for obtaining a better understanding of apoptotic cell death caused by BHA.

Acknowledgements We thank Dr. Mitsutaka Yoshida, Division of Electron Microscopy, Central Laboratory of Medical Science, Juntendo University for his effort with electron microscopy.

\section{REFERENCES}

1) Ishiwata H., Fukushima A., Abe Y., Yamada T., Nishijima M., Fukasawa Y., J. Food Hyg. Soc. Japan, 41, 86-93 (2000).

2) Van Dokkum W., De Vos R. H., Cloughley F. A., Hulshol K. F., Dukel F., Wijsman J. A., Br. J. Nutr., 48, 223-231 (1982).

3) Leclercq C., Arcella D., Turrini A., Food Chem. Toxicol., 38, 10751084 (2000).

4) Maziero G. C., Baunwart C., Toledo M. C., Food Addit. Contam., 18, $365-373$ (2001).

5) Conacher H. B. S., Iverson F., Lau P.-Y., Page B. D., Food Chem. Toxicol., 24, 1159-1162 (1986).

6) Reddy B. S., Maeura Y., J. Natl. Cancer Inst., 72, 1181-1187 (1984).

7) Horváthová E., Slameňová D., Bonatti S., Abbondandolo A., Neoplasma, 46, 356-362 (1999).

8) Lin Y. S., Kuo H. L., Kuo C. F., Wang S. T., Yang B. C., Chen H. I., Med. Sci. Sports Exerc., 31, 1594-1598 (1999).

9) Brekke O.-L., Shalaby M. R., Sundan A., Espevik T., Bjerve K. S., Cytokine, 4, 269-280 (1992).

10) Vercammen D., Beyaert R., Denecker G., Goossens V., Loo G. V., Declercq W., Grooten J., Fiers W., Vandenabeele P., J. Exp. Med., 187, 1477-1485 (1998).

11) Ratan R. R., Murphy T. H., Baraban J. M., J. Neurochem., 62, 376379 (1994).

12) Verhaegen S., McGowan A. J., Brophy A. R., Fernandes R. S., Cotter T. G., Biochem. Pharmacol., 50, $1021-1029$ (1995).

13) Hayashi T., Catanzaro A., Rao S. P., Infect. Immun., 65, 5262-5271 
(1997).

14) Ito N., Fukushima S., Hagiwara A., Shibata M., Ogiso T., J. Natl. Cancer Inst., 70, 343-352 (1983).

15) Ito N., Fukushima S., Imaida K., Sakata T., Masui T., Gann, 74, 459461 (1983).

16) Kirlin W. G., Cai J., DeLong M. J., Patten E. J., Jones D. P., J. Nutr., 129, 1827-1835 (1999).

17) Babich H., Borenfreund E., J. Pharm. Sci., 79, 592-594 (1990).

18) Yu R., Mandlekar S., Kong A. T., Mol. Pharmacol., 58, 431-437 (2000).

19) Fusi F., Sgaragli G., Murphy M. P., Biochem. Pharmacol., 43, 12031208 (1992).

20) Thompson D., Moldéus P., Biochem. Pharmacol., 37, 2201-2207 (1988).

21) Yokoyama Y., Okubo T., Ozawa S., Nagai F., Ushiyama K., Kano I., Shioda M., Kubo H., Takemura M., Namiki H., Yasugi E., Oshima M., Seyama Y., Kano K., FEBS Lett., 412, 153-156 (1997).

22) Troyano A., Fernandez C., Sancho P., de Blas E., Aller P., J. Biol. Chem., 276, 47107-47115 (2001).

23) Salvioli S., Ardizzoni A., Franceschi C., Cossarizza A., FEBS Lett., 411, 77-82 (1997).

24) Shah G. M., Shah R. G., Poirier G. G., Biochem. Biophys. Res. Commun., 229, 838-844 (1996).

25) Hissin P. J., Hilf R., Anal. Biochem., 74, 214 -226 (1976).

26) Cornelissen J., Wanders R. J., Van Gennip A. H., Van den Bogert C.,
Voûte P. A., Van Kuilenburg A. B., Biochem. Pharmacol., 49, 471477 (1995).

27) Trounce I. A., Kim Y. L., Jun A. S., Wallace D. C., Methods Enzymol., 264, 484-509 (1996).

28) Cardoso S. M., Pereira C., Oliveira R., Free Radic. Biol. Med., 26, 3 13 (1999).

29) Kroemer G., Dallaporta B., Resche-Rigon M., Annu. Rev. Physiol., 60, 619-642 (1998).

30) Cryns V., Yuan J., Genes Dev., 12, 1551-1570 (1998).

31) Thornberry N. A., Lazebnik Y., Science, 281, 1312-1316 (1998).

32) Fones E., Amigo H., Gallegos K., Guerrero A., Ferreira J., Biochem. Pharmacol., 38, 3443-3451 (1989).

33) Ferreira J., Biochem. Pharmacol., 40, 677-684 (1990).

34) Alleva R., Tomasetti M., Andera L., Gellert N., Borghi B., Weber C., Murphy M. P., Neuzil J., FEBS Lett., 503, 46-50 (2001).

35) Merad-Boudia M., Nicole A., Santiard-Baron D., Saillé C., CeballosPicot I., Biochem. Pharmacol., 56, 645-655 (1998).

36) Visarius T. M., Putt D. A., Schare J. M., Pegouske D. M., Lash L. H., Biochem. Pharmacol., 52, 259-272 (1996).

37) Lash L. H., Putt D. A., Biochem. Pharmacol., 58, 897—907 (1999).

38) Leist M., Single B., Castoldi A. F., Kühnle S. K., Nicotera P., J. Exp. Med., 185, 1481-1486 (1997).

39) Lieberthal W., Menza S. A., Levine J. S., Am. J. Physiol., 274, F315F327 (1998). 